\title{
Accuracy of Orthodontic 3D Printed Retainers versus Thermoformed Retainers
}

\author{
Ahmed A. Nasef', Amr R. El-Beialy ${ }^{2,3,4}$, Faten Hussein Kamel Eid², Yehya A. Mostafa ${ }^{2,3,4}$ \\ ${ }^{1}$ Department of Orthodontics and Dentofacial Orthopedics, Faculty of Oral and Dental Medicine, \\ The British University in Egypt, Cairo, Egypt \\ ${ }^{2}$ Department of Orthodontics and Dentofacial Orthopedics, Faculty of Oral and Dental Medicine, Cairo University, Cairo, Egypt \\ ${ }^{3}$ MORTH Program, Faculty of Oral and Dental Medicine, Cairo University, Cairo, Egypt \\ ${ }^{4}$ MORTH Program, Faculty of Oral and Dental Medicine, Future University, Cairo, Egypt \\ Email: aanasef@gmail.com, ahmed.nasef@bue.edu.eg, amr.elbeialy@dentistry.cu.edu.eg, amrelbeialy@gmail.com
}

How to cite this paper: Nasef, A.A., El-Beialy, A.R., Eid, F.H.K. and Mostafa, Y.A. (2017) Accuracy of Orthodontic 3D Printed Retainers versus Thermoformed Retainers. Open Journal of Medical Imaging, 7, 169-179.

https://doi.org/10.4236/ojmi.2017.74017

Received: March 30, 2017

Accepted: October 15, 2017

Published: October 18, 2017

Copyright $\odot 2017$ by authors and Scientific Research Publishing Inc. This work is licensed under the Creative Commons Attribution International License (CC BY 4.0).

http://creativecommons.org/licenses/by/4.0/

\begin{abstract}
Background: The integration of the current technology of $\mathrm{CBCT}$ and $3 \mathrm{D}$ CAD/CAM technology has great potential in the field of orthodontics, which is not yet fully investigated. The purpose of this article is to evaluate the accuracy of $3 \mathrm{D}$ printed retainers in comparison to vacuum formed retainers. $\mathrm{Me}$ thods: Alginate impressions were taken for ten patients who have a CBCT scan. A 3D printed retainer and vacuum formed retainer were fabricated. Linear measurements were measured by two assessors using digital caliper. Every measurement on the 3D printed retainer was compared to the corresponding measurement on the thermoformed retainer. The linear measurements were Inter-canine width, Inter-premolar width (first and second premolars), Inter-molar width, Canine-midline length (both sides) and Canine-molar length (both sides). Intra-observer, and inter-observer reliability measurements were done. Results: Results showed excellent intra-observer reliability for the thermoformed retainer and the $3 \mathrm{D}$ printed retainer. Inter-observer measurements showed strong agreement between the measurements of the two assessors, for both retainers. The comparison of the thermoformed retainer to the $3 \mathrm{D}$ printed retainer showed high statistical agreement, except for the canine-molar on the right side, but with no clinical significance, $p$ value of 0.038 and mean difference 0.19 . Conclusions: The new method for fabricating a $3 \mathrm{D}$ printed retainer is accurate and reliable in comparison to the vacuum formed retainer (conventional method). CBCT proved to be efficient for fabrication of a custom made appliances.
\end{abstract}

\section{Keywords}

3D Printing, Additive Manufacturing, Digital Orthodontics, Dentistry, Orthodontics, Orthodontic Appliance Design, Orthodontic Appliances, 
Orthodontic Retainers, Technology, Dental, Orthodontic Appliance Design

\section{Manuscript Proper}

Digital technology is revolutionizing our orthodontic discipline. The $3 \mathrm{D}$ technology [1] [2] [3] as one of the most inspiring current digital technologies, has enhanced our capabilities, allowed better visualization and more effective communication with the patients. As far as the orthodontic discipline, this $3 \mathrm{D}$ technology has paved the way for virtually designing and fabricating orthodontic appliances. It is the current leap for orthodontic computer-aided design (CAD) and computer-aided manufacturing (CAM) techniques [4] [5] [6].

Recently, cone beam computed tomography was integrated with the power of $3 \mathrm{D}$ printing to fabricate a retainer similar to the vacuum formed retainer [7]. This method empowered the potential of orthodontic 3D technology, 3D printing and the future of custom made appliances' fabrication with a simple scan.

The use of this technology augments the digital archiving and retrieval of the dentition for fabrication of a retainer. Besides, it eliminated the need for an extra impression. Unlike other techniques, this method used simple non-custom made software for fabricating virtual appliances, rather than sophisticated instruments [6].

The aim of this article is to evaluate the dimensional accuracy of the $3 \mathrm{D}$ printed retainer in comparison to the conventional vacuum formed retainer.

\section{Materials and Methods}

The following procedures were applied on a sample of ten patients. All patients had properly aligned teeth post-orthodontic treatment. The patients were selected who have CBCT post-orthodontic treatment and need to fabricate a thermoformed retainer. Records and dental models for appliance fabrication can be obtained from a single CBCT. All patients signed a consent before CBCT scan.

The thermoformed retainer was fabricated using the conventional method, where the patients' stone models were trimmed and a retainer sheet $1 \mathrm{~mm}$ in thickness was vacuum-pressed on each model (Figure 1).

Simultaneously, 3D digital dentition was acquired via the CBCT of the patients. The upper and/or lower dentitions were separated (Figure 2). Using 3D software, the retainer was virtually designed on the digital dentition (Figures 3(a)-(d)) utilizing retopology. The retainer was then three dimensionally printed (Figure 3) using Formiga p100 3D printing machine (Figure 4). The detailed technique of this method was explained in a previous article [7].

Hence, a 3D printed retainer, and a thermoformed retainer were acquired for each patient. The accuracy of the $3 \mathrm{D}$ printed retainers were evaluated and compared to the vacuum formed retainers. Linear measurements were taken on 


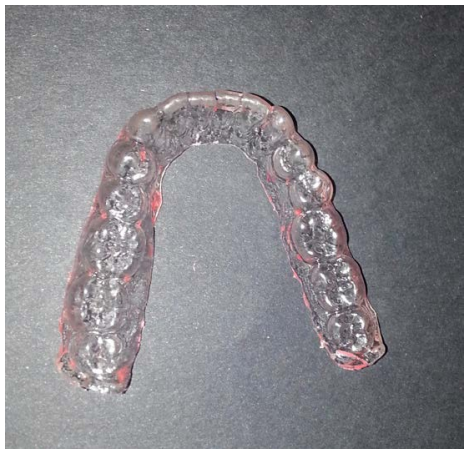

(a)

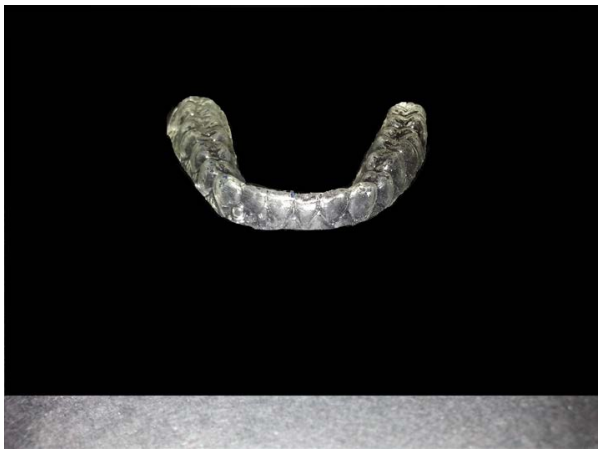

(b)

Figure 1. Conventional thermoformed retainer.

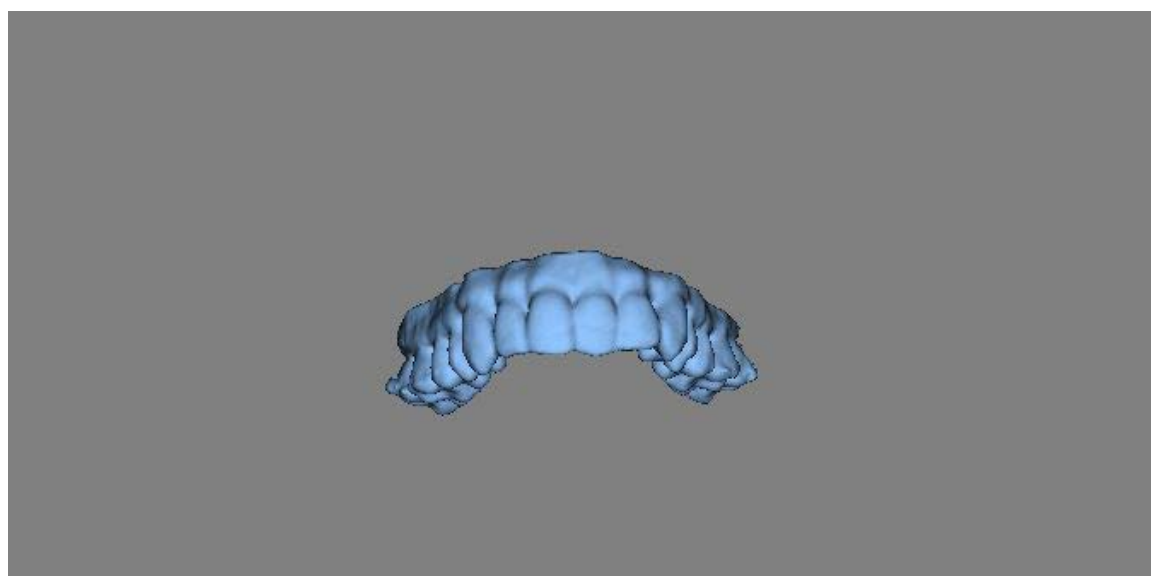

Figure 2. Isolated upper arch.

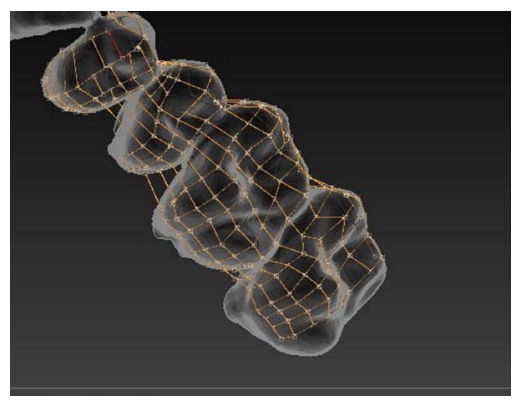

(a)

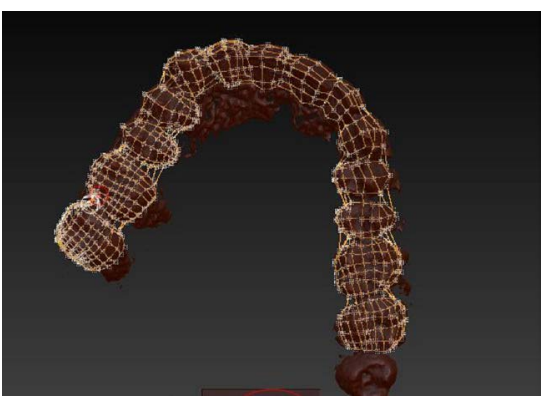

(b)

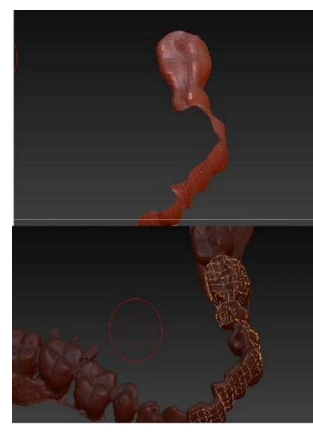

(c)

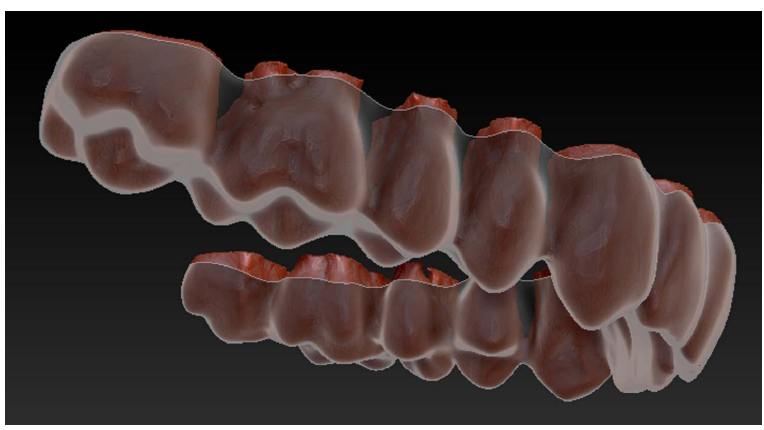

(d)

Figure 3. Virtually designed retainer. 


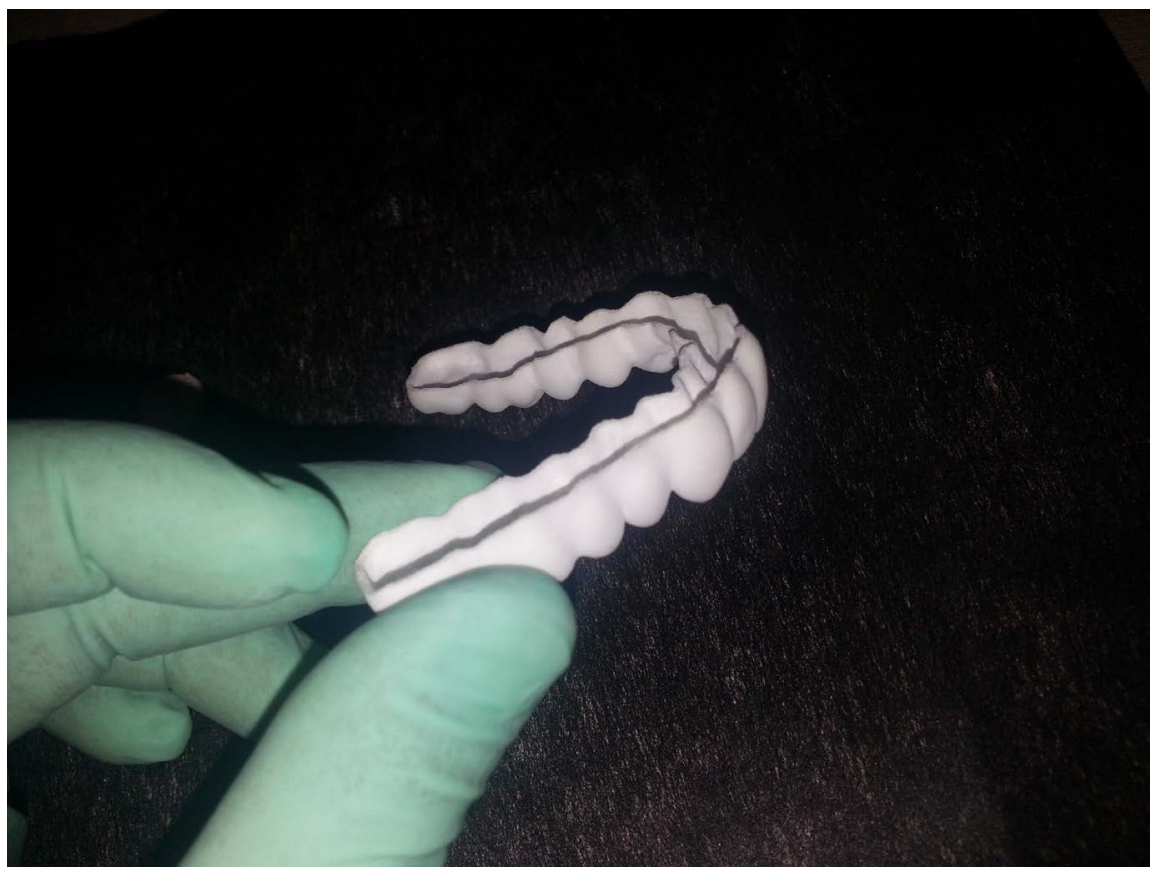

Figure 4. 3D printed retainer.

3D printer retainers as well as the vacuum formed retainers using electronic digital caliper with an accuracy of $0.01 \mathrm{~mm}$ (Figure 5). Every measurement on the $3 \mathrm{D}$ printed retainer was compared to corresponding measurement on the vacuum formed retainer.

The linear measurements were (Figure 6):

1) Inter-canine width: measured between the cusp tips of the right and left canines.

2) Inter-premolar width: measured between the buccal cusp tips of the first premolars as well as the second premolars.

3) Inter-molar width: measured between the mesiobuccal cusp tips of the right and left first molars.

4) Canine cusp tip to mesiobuccal cusp of the first permanent molar (measured on the right and left sides).

5) Canine tip to the midline between the two central incisors (measured on the right and left sides).

A first assessor other than the primary researcher identified the points (cusp tips) accurately on the retainers and took the measurements. To calculate the intra and inter observer reliability the same measurements were repeated by a second assessor and the whole sample was reassessed by one of the assessors for intra-observer reliability.

Quantitative data was presented as mean and standard deviation values. Data was explored for normality by checking the data distribution, calculating the mean and median values and using Kolmogorov-Smirnov and Shapiro-Wilk tests. Paired-t-test was used in comparison between groups, observers, and readings. Intra-class correlation was used to assess agreement between observers 


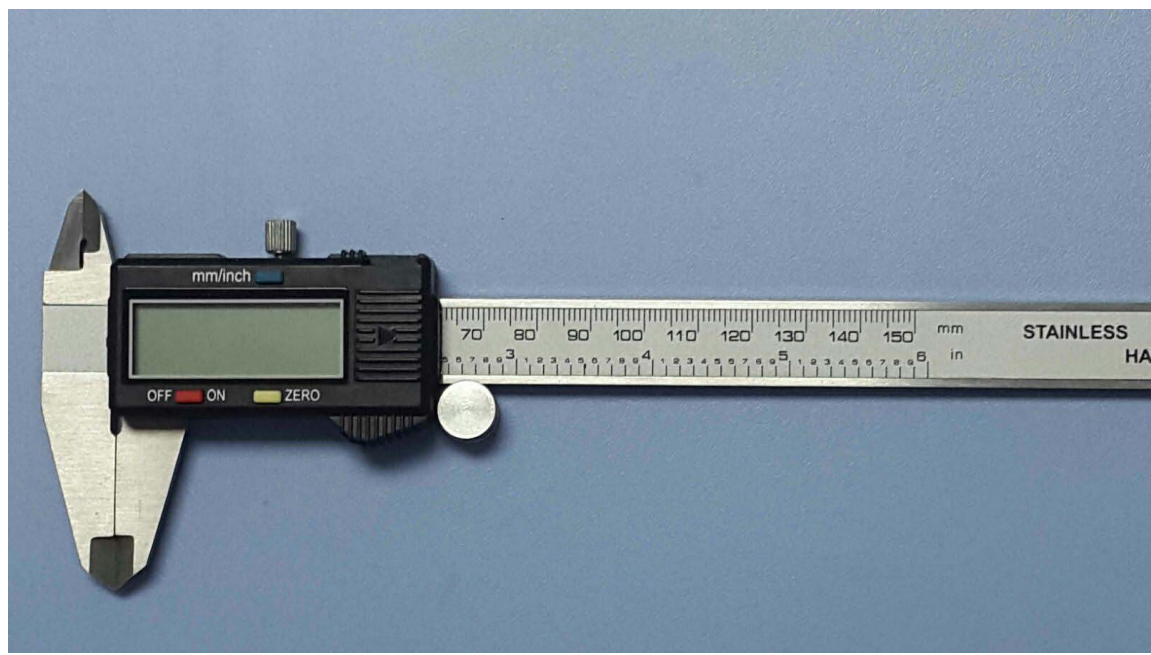

Figure 5. Electronic digital caliper used for measurement.

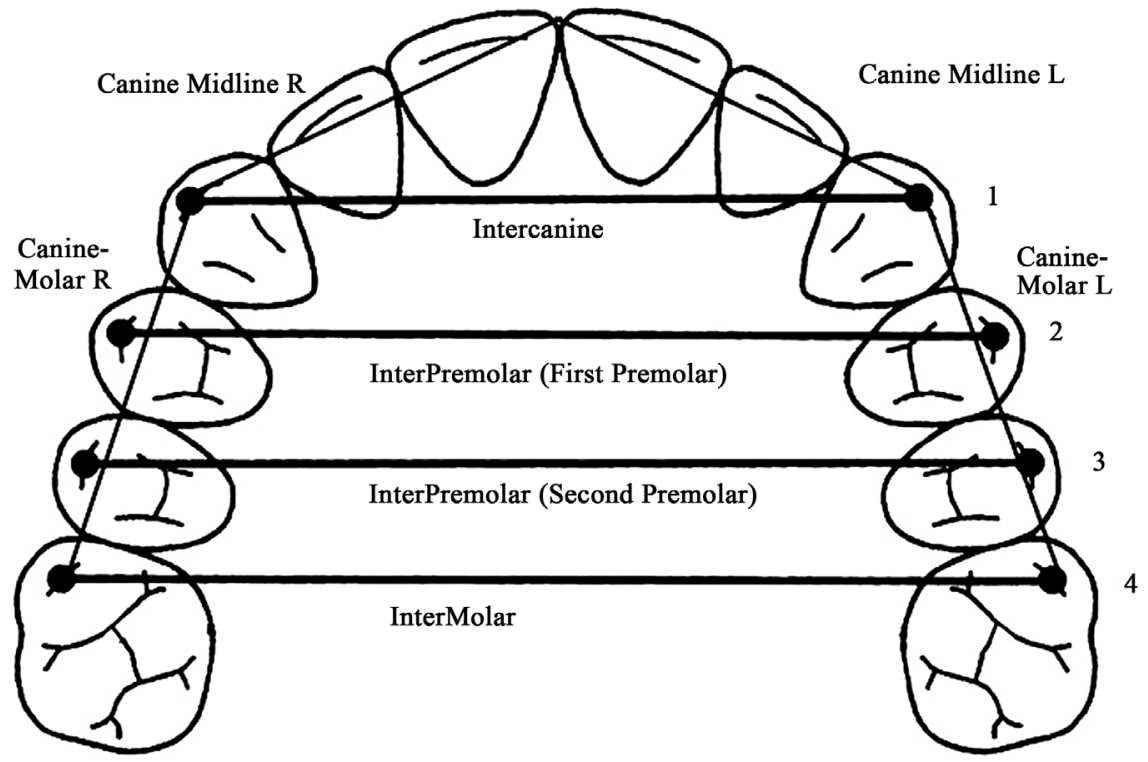

Figure 6. Diagram showing the linear measurements evaluated.

and readings. The significance level was set at $P \leq 0.05$. Statistical analysis was performed with IBM $^{1}$ SPSS $^{2}$ Statistics Version 20 for Windows.

\section{Results}

The results of the intra-observer comparison showed great reliability between the two readings in all measurements for the thermoformed retainer (Table 1), except for the canine-molar right was statistically significant with $p$ value of 0.038 and mean difference of $0.19 \mathrm{~mm}$, but which was clinically insignificant. However, the intra-observer results showed high reliability for the $3 \mathrm{D}$ printed retainer (Table 2).

${ }^{1}$ IBM Corporation, NY, USA.

${ }^{2}$ SPSS, Inc., an IBM Company. 
Table 1. Showing the intra-observer reliability between the two readings in all measurements for the thermoformed retainer.

\begin{tabular}{|c|c|c|c|c|c|c|}
\hline Measurement & Reading & Mean & $\begin{array}{l}\text { Standard } \\
\text { Deviation }\end{array}$ & Mean diff & $\begin{array}{l}\text { Standard of } \\
\text { Error } \\
\text { Mean diff }\end{array}$ & $P$ value \\
\hline \multirow{2}{*}{ Inter canine } & 1 & 31.4740 & 5.75803 & \multirow{2}{*}{0.011} & \multirow{2}{*}{0.03335} & \multirow{2}{*}{0.749} \\
\hline & 2 & 31.4850 & 5.80016 & & & \\
\hline \multirow{2}{*}{ Inter premolar 4} & 1 & 38.3080 & 5.27847 & \multirow{2}{*}{-0.060} & \multirow{2}{*}{0.05760} & \multirow{2}{*}{0.325} \\
\hline & 2 & 38.2480 & 5.24673 & & & \\
\hline \multirow{2}{*}{ Inter premolar 5} & 1 & 43.7500 & 5.03196 & \multirow{2}{*}{0.064} & \multirow{2}{*}{0.07367} & \multirow{2}{*}{0.408} \\
\hline & 2 & 43.8140 & 5.02348 & & & \\
\hline \multirow{2}{*}{ Inter molar } & 1 & 31.4740 & 5.75803 & \multirow{2}{*}{0.091} & \multirow{2}{*}{0.08829} & \multirow{2}{*}{0.330} \\
\hline & 2 & 31.4850 & 5.80016 & & & \\
\hline \multirow{2}{*}{ Canine-molar right } & 1 & 21.4500 & 1.24846 & \multirow{2}{*}{0.190} & \multirow{2}{*}{0.06520} & \multirow{2}{*}{$0.017^{*}$} \\
\hline & 2 & 21.6400 & 1.23566 & & & \\
\hline \multirow{2}{*}{ Canine-molar left } & 1 & 21.3270 & 1.30977 & \multirow{2}{*}{0.079} & \multirow{2}{*}{0.06752} & \multirow{2}{*}{0.272} \\
\hline & 2 & 21.4060 & 1.28940 & & & \\
\hline \multirow{2}{*}{ Canine-midline right } & 1 & 16.9470 & 3.62351 & \multirow{2}{*}{-0.018} & \multirow{2}{*}{0.05444} & \multirow{2}{*}{0.748} \\
\hline & 2 & 16.9290 & 3.67068 & & & \\
\hline \multirow{2}{*}{ Canine-midline left } & 1 & 16.7890 & 3.12837 & \multirow{2}{*}{0.128} & \multirow{2}{*}{0.08143} & \multirow{2}{*}{0.150} \\
\hline & 2 & 16.9170 & 3.22523 & & & \\
\hline
\end{tabular}

Table 2. Showing the intra-observer reliability between the two readings in all measurements for the $3 \mathrm{D}$ printed retainer.

\begin{tabular}{|c|c|c|c|c|c|c|}
\hline Measurement & Reading & Mean & $\begin{array}{l}\text { Standard } \\
\text { deviation }\end{array}$ & Mean diff & $\begin{array}{l}\text { Standard of } \\
\text { error mean dif- } \\
\text { ference }\end{array}$ & $P$ value \\
\hline \multirow[b]{2}{*}{ Inter canine } & 1 & 31.5200 & 5.80848 & \multirow[b]{2}{*}{0.188} & \multirow[b]{2}{*}{0.11951} & \multirow[b]{2}{*}{0.15} \\
\hline & 2 & 31.7080 & 6.00103 & & & \\
\hline \multirow{2}{*}{ Inter premolar 4} & 1 & 38.4890 & 5.27680 & \multirow{2}{*}{-0.026} & \multirow{2}{*}{0.10511} & \multirow{2}{*}{0.81} \\
\hline & 2 & 38.4630 & 5.41781 & & & \\
\hline \multirow[b]{2}{*}{ Inter premolar 5} & 1 & 43.8460 & 5.39636 & \multirow[b]{2}{*}{0.068} & \multirow[b]{2}{*}{0.06841} & \multirow{2}{*}{0.346} \\
\hline & 2 & 43.9140 & 5.41846 & & & \\
\hline \multirow{2}{*}{ Inter molar } & 1 & 31.5200 & 5.80848 & \multirow{2}{*}{0.171} & \multirow{2}{*}{0.11758} & \multirow{2}{*}{0.18} \\
\hline & 2 & 31.7080 & 6.00103 & & & \\
\hline \multirow{2}{*}{ Canine-molar right } & 1 & 21.6290 & 1.06282 & \multirow{2}{*}{0.104} & \multirow{2}{*}{0.0723} & \multirow{2}{*}{0.184} \\
\hline & 2 & 21.7330 & 1.02605 & & & \\
\hline \multirow{2}{*}{ Canine-molar left } & 1 & 21.6010 & 1.26958 & \multirow{2}{*}{0.049} & \multirow{2}{*}{0.03407} & \multirow{2}{*}{0.184} \\
\hline & 2 & 21.6500 & 1.25416 & & & \\
\hline \multirow{2}{*}{ Canine-midline right } & 1 & 17.1360 & 3.67017 & \multirow{2}{*}{0.016} & \multirow{2}{*}{0.06013} & \multirow{2}{*}{0.796} \\
\hline & 2 & 17.1520 & 3.71283 & & & \\
\hline \multirow{2}{*}{ Canine-midline left } & 1 & 16.8530 & 3.25482 & \multirow{2}{*}{0.011} & \multirow{2}{*}{0.0677} & \multirow{2}{*}{0.875} \\
\hline & 2 & 16.8640 & 3.21253 & & & \\
\hline
\end{tabular}


The analysis of the inter-observer measurements showed strong agreement between the measurements of the two assessors. This was apparent for the thermoformed retainer as well as the 3D printed retainer (Table $3 \&$ Table 4 ). The solitary measurement of the Canine-midline on the right side was statistically significant but with no clinically significance.

The comparison of the thermoformed retainer to the $3 \mathrm{D}$ printed retainer displayed in Table 5, showed high statistical agreement, except for the canine-molar on the left side, but with no clinically significance.

\section{Discussion}

Orthodontic retention phase is one of the most important phases in orthodontic treatment. Maintaining tooth alignment after orthodontic treatment has always been an important goal for orthodontists. Without retention, the treatment would be useless as relapse occur in almost all cases with variable amount [8]. Since technology is currently shaping our profession, it would be sensible to harness the power of technology to enable orthodontists to improve the post-treatment phase. That being said, $\mathrm{CBCT}$, 3D softwares and 3D printing were used in this study to digitally design and fabricate $3 \mathrm{D}$ virtual retainer.

Table 3. Showing the inter-observer measurements for the vacuum formed retainer.

\begin{tabular}{|c|c|c|c|c|c|c|}
\hline Measurement & Assessor & Mean & $\begin{array}{l}\text { Standard } \\
\text { deviation }\end{array}$ & $\begin{array}{c}\text { Mean } \\
\text { difference }\end{array}$ & $\begin{array}{l}\text { Standard of error } \\
\text { mean difference }\end{array}$ & $P$ value \\
\hline \multirow[b]{2}{*}{ Inter canine } & 1 & 31.4740 & 5.75803 & \multirow[b]{2}{*}{0.02500} & \multirow[b]{2}{*}{0.03801} & \multirow{2}{*}{0.527} \\
\hline & 2 & 31.4990 & 5.75853 & & & \\
\hline \multirow{3}{*}{ Inter premolar 4} & 1 & 38.3080 & 5.27847 & \multirow{3}{*}{0.00600} & \multirow{3}{*}{0.07190} & \multirow{3}{*}{0.935} \\
\hline & & & & & & \\
\hline & 2 & 38.3140 & 5.19314 & & & \\
\hline \multirow{3}{*}{ Inter premolar 5} & 1 & 43.7500 & 5.03196 & \multirow{3}{*}{0.04500} & \multirow{3}{*}{0.06114} & \multirow{3}{*}{0.480} \\
\hline & & & & & & \\
\hline & 2 & 43.7950 & 5.05948 & & & \\
\hline \multirow{3}{*}{ Inter molar } & 1 & 49.3060 & 4.61659 & \multirow{3}{*}{0.12600} & \multirow{3}{*}{0.10523} & \multirow{3}{*}{0.262} \\
\hline & & & & & & \\
\hline & 2 & 49.4320 & 4.60217 & & & \\
\hline \multirow{3}{*}{ Canine-molar left } & 1 & 21.3270 & 1.30977 & \multirow{3}{*}{0.10800} & \multirow{3}{*}{0.07038} & \multirow{3}{*}{0.159} \\
\hline & & & & & & \\
\hline & 2 & 21.4350 & 1.32023 & & & \\
\hline \multirow{3}{*}{ Canine-molar right } & 1 & 21.4500 & 1.24846 & \multirow{3}{*}{0.008} & \multirow{3}{*}{0.0498} & \multirow{3}{*}{0.879} \\
\hline & & & & & & \\
\hline & 2 & 21.4580 & 1.22363 & & & \\
\hline \multirow{3}{*}{ Canine-midline left } & 1 & 16.7890 & 3.12837 & \multirow{3}{*}{0.02100} & \multirow{3}{*}{0.05378} & \multirow{3}{*}{0.705} \\
\hline & & & & & & \\
\hline & 2 & 16.8100 & 3.17954 & & & \\
\hline \multirow{3}{*}{ Canine-midline right } & 1 & 16.9470 & 3.62351 & \multirow{3}{*}{0.11600} & \multirow{3}{*}{0.06930} & \multirow{3}{*}{0.128} \\
\hline & & & & & & \\
\hline & 2 & 17.0630 & 3.80274 & & & \\
\hline
\end{tabular}


Table 4. Results of the two assessors of all measurements in the 3D printed retainer.

\begin{tabular}{|c|c|c|c|c|c|c|}
\hline Measurement & Assessor & Mean & $\begin{array}{c}\text { Std. } \\
\text { deviation }\end{array}$ & $\begin{array}{c}\text { Mean } \\
\text { diff }\end{array}$ & $\begin{array}{l}\text { Std. error } \\
\text { mean } \\
\text { difference }\end{array}$ & $P$ value \\
\hline \multirow{2}{*}{ Inter canine } & 1 & 31.5200 & 5.80848 & \multirow{2}{*}{0.01900} & \multirow{2}{*}{0.03647} & \multirow{2}{*}{0.615} \\
\hline & 2 & 31.5390 & 5.85119 & & & \\
\hline \multirow{2}{*}{ Inter premolar 4} & 1 & 38.4890 & 5.27680 & \multirow{2}{*}{0.12200} & \multirow{2}{*}{0.07351} & \multirow{2}{*}{0.131} \\
\hline & 2 & 38.3670 & 5.25671 & & & \\
\hline \multirow{2}{*}{ Inter premolar 5} & 1 & 43.8460 & 5.39636 & \multirow{2}{*}{0.05000} & \multirow{2}{*}{0.08551} & \multirow{2}{*}{0.573} \\
\hline & 2 & 43.8960 & 5.23351 & & & \\
\hline \multirow{2}{*}{ Inter molar } & 1 & 49.3860 & 4.87203 & \multirow{2}{*}{0.11600} & \multirow{2}{*}{0.09466} & \multirow{2}{*}{0.252} \\
\hline & 2 & 49.5020 & 4.85234 & & & \\
\hline \multirow{2}{*}{ Canine-molar left } & 1 & 21.6010 & 1.26958 & \multirow{2}{*}{0.08900} & \multirow{2}{*}{0.07650} & \multirow{2}{*}{0.275} \\
\hline & 2 & 21.5120 & 1.12056 & & & \\
\hline \multirow{2}{*}{ Canine-molar right } & 1 & 21.6290 & 1.06282 & \multirow{2}{*}{0.05300} & \multirow{2}{*}{0.04085} & \multirow{2}{*}{0.227} \\
\hline & 2 & 21.5760 & 1.09264 & & & \\
\hline \multirow{2}{*}{ Canine-midline left } & 1 & 16.8530 & 3.25482 & \multirow{2}{*}{0.02000} & \multirow{2}{*}{0.05890} & \multirow[b]{2}{*}{0.742} \\
\hline & 2 & 16.8330 & 3.23380 & & & \\
\hline \multirow{2}{*}{ Canine-midline right } & 1 & 17.1360 & 3.67017 & \multirow{2}{*}{0.11000} & \multirow{2}{*}{0.04738} & \multirow{2}{*}{$0.045^{*}$} \\
\hline & 2 & 17.0260 & 3.74751 & & & \\
\hline
\end{tabular}

*Statistically significant.

Table 5. Showing the agreement in measurements between the vacuum formed retainer and the $3 \mathrm{D}$ printed retainer.

\begin{tabular}{|c|c|c|c|c|c|c|}
\hline Measurement & Retainer & Mean & $\begin{array}{c}\text { Std. } \\
\text { deviation }\end{array}$ & $\begin{array}{c}\text { Mean } \\
\text { diff }\end{array}$ & $\begin{array}{l}\text { Std. error } \\
\text { mean } \\
\text { difference }\end{array}$ & $P$ value \\
\hline \multirow{2}{*}{ Inter canine } & Vacuum & 31.4740 & 5.75803 & \multirow{2}{*}{0.046} & \multirow{2}{*}{0.11} & \multirow{2}{*}{0.677} \\
\hline & $3 \mathrm{D}$ & 31.5200 & 5.80848 & & & \\
\hline \multirow{2}{*}{ Inter premolar 4} & Vacuum & 38.3080 & 5.27847 & \multirow{2}{*}{0.181} & \multirow{2}{*}{0.14} & \multirow{2}{*}{0.245} \\
\hline & $3 \mathrm{D}$ & 38.4890 & 5.27680 & & & \\
\hline \multirow{2}{*}{ Inter premolar 5} & Vacuum & 43.7500 & 5.03196 & \multirow{2}{*}{0.096} & \multirow{2}{*}{0.22} & \multirow{2}{*}{0.666} \\
\hline & $3 \mathrm{D}$ & 43.8460 & 5.39636 & & & \\
\hline \multirow{2}{*}{ Inter molar } & Vacuum & 49.3060 & 4.61659 & \multirow{2}{*}{0.08} & \multirow{2}{*}{0.24} & \multirow{2}{*}{0.744} \\
\hline & $3 \mathrm{D}$ & 49.3860 & 4.87203 & & & \\
\hline \multirow{2}{*}{ Canine-midline left } & Vacuum & 16.7890 & 3.12837 & \multirow{2}{*}{0.06} & \multirow{2}{*}{0.07} & \multirow{2}{*}{0.432} \\
\hline & $3 \mathrm{D}$ & 16.8530 & 3.25482 & & & \\
\hline \multirow{2}{*}{ Canine-midline right } & Vacuum & 16.9470 & 3.62351 & \multirow{2}{*}{0.19} & \multirow{2}{*}{0.07} & \multirow{2}{*}{$0.038^{*}$} \\
\hline & $3 \mathrm{D}$ & 17.1360 & 3.67017 & & & \\
\hline \multirow{2}{*}{ Canine-molar left } & Vacuum & 21.3270 & 1.30977 & \multirow{2}{*}{0.27} & \multirow{2}{*}{0.12} & \multirow{2}{*}{0.054} \\
\hline & $3 \mathrm{D}$ & 21.6010 & 1.26958 & & & \\
\hline \multirow{2}{*}{ Canine-molar right } & Vacuum & 21.4500 & 1.24846 & \multirow{2}{*}{0.18} & \multirow{2}{*}{0.11} & \multirow{2}{*}{0.151} \\
\hline & $3 \mathrm{D}$ & 21.6290 & 1.06282 & & & \\
\hline
\end{tabular}

${ }^{*}$ Statistically significant. 
The procedure starts with attaining a digital replica of the teeth; with its inherent advantages. Firstly, it opened a door for digital archiving and retrieval of the orthodontic model at any point in time. Secondly, it eliminated the step of taking an impression, which saves time and is more convenient to the patient. It also facilitates the exchange of the 3D data between practitioners as well as dental labs. In this study, 3D data was obtained by CBCT; with accuracy already proven.

The 3D digital retainer is designed on a personal computer using 3D software, and then printed using a 3D printer machine. The idea and the procedure details were previously published by the same authors [7].

To evaluate the accuracy of the $3 \mathrm{D}$ formed retainer to the conventional vacuum formed retainer, measurements on both retainers were compared. Similar to other studies [9] [10] [11] [12] [13], the measurements were done using a digital caliper because of its accuracy and simplicity. The measurements were made by two separate assessors [14]. Each retainer was measured and the data was tabulated. One of the assessors re-measured all the retainers again to determine the intra-observer reliability.

The presented results showed that this new technique is promising and accurate, with no statistically significant difference between the two retainers, the two assessors, nor within the same assessor. The minimal statistical significance depicted for few measurements; without clinical significance, could be reverted to the short distances measured, where a small difference in measurements represent a high percentage of the original measurement. The results showed the possibility of creating a retainer accurately on patient's teeth without an impression. Hence, in consensus with other techniques, working with digital replicas proved to be accurate and reliable [15] [16] [17].

Computer assisted designing and manufacturing has been introduced in many articles and proved to be promising [5] [6] [7] [18]. Usually CAD/CAM technology need sophisticated custom made tools to virtually design and manufacture an appliance [6]. This research uses commercially available softwares and $3 \mathrm{D}$ printers.

Some of the technology used in this study might be commercially available but relatively expensive, such as $3 \mathrm{D}$ printers. However, as time passes this technology will become developed and financially affordable. So it might not be totally feasible nowadays to implement this in every clinic but it shows the possibilities that can be a reality in the near future in our practice. These latest technologies help us to improve our practice and eventually the convenience and the final outcome of treatment.

One problem encountered during virtual designing of the $3 \mathrm{D}$ retainer was the absence of soft tissue in the digital dental model. The gingival due to its lack of radio-density is invisible. Therefore, the extensions of the digital retainer had to be designed away from the potential interdental papilla and should not be extended too much towards the gingival area. The process has a learning curve to be able to create the mesh virtually using the "retopology" method. However, 
this method could be easily automated saving even more time in the process.

The $3 \mathrm{D}$ printed retainer was printed out of a white material. This material is originally in a powder form and is laser sintered. Due to the few numbers of 3D printers and fewer materials available, this material was the best available material that provided accuracy and synchrony with the 3D printer for fabrication of such thin appliances. Therefore, it is recommended to replicate this technique using a clear bio-compatible material. Moreover, the new 3D fabricated appliances should be evaluated in cases that require active teeth movement.

This technique paves the road for enhanced digital orthodontics, digital appliance designing and fabrication. Utilizing this technique enables the orthodontist to fabricate a retainer without the need of an impression as well as obtaining digital dental models and radiographs from a single CBCT scan. Incorporating available 3D softwares to move the teeth then fabricate the retainer can be easily done so that any minimal adjustments can be done. Using digital technology in designing and fabricating the retainer allows customization of the appliances.

\section{Conclusion}

This new method for fabricating a 3D printed retainer is accurate and reliable in comparison to the conventional vacuum formed. CBCT and 3D printing proved to be efficient for fabrication of custom made digital appliances, and entails a potential for the digital orthodontic future.

\section{Acknowledgements}

This study is a self-funded study, with no contribution from any institutional or departmental origin.

\section{Conflict}

There is no conflict of interest by any means.

\section{References}

[1] Martin, C.B., Chalmers, E.V., McIntyre, G.T., Cochrane, H.S. and Mossey, P.A. (2015) Orthodontic Scanners: What's Available? Journal of Orthodontics, 42, 136-143. https://doi.org/10.1179/1465313315Y.0000000001

[2] Swennen, G.R.J., Mollemans, W. and Schutyser, F. (2009) Three-Dimensional Treatment Planning of Orthognathic Surgery in the Era of Virtual Imaging. Journal of Oral and Maxillofacial Surgery, 67, 2080-2092.

https://doi.org/10.1016/j.joms.2009.06.007

[3] Kapila, S., Conley, R.S. and Harrell, W.E. (2011) The Current Status of Cone Beam Computed Tomography Imaging in Orthodontics. Dentomaxillofacial Radiology, 40, 24-34. https://doi.org/10.1259/dmfr/12615645

[4] Cassetta, M., Pandolfi, S. and Giansanti, M. (2015) Minimally Invasive Corticotomy in Orthodontics: A New Technique Using A CAD/CAM Surgical Template. International Journal of Oral and Maxillofacial Surgery, 44, 830-833. https://doi.org/10.1016/j.ijom.2015.02.020

[5] Lauren, M. and McIntyre, F. (2008) A New Computer-Assisted Method for Design 
and Fabrication of Occlusal Splints. American Journal of Orthodontics and Dentofacial Orthopedics, 133, S130-S135. https://doi.org/10.1016/j.ajodo.2007.11.018

[6] Al Mortadi, N., Eggbeer, D., Lewis, J. and Williams, R.J. (2012) CAD/CAM/AM Applications in the Manufacture of Dental Appliances. American Journal of Orthodontics and Dentofacial Orthopedics, 142, 727-733.

https://doi.org/10.1016/j.ajodo.2012.04.023

[7] Nasef, A.A., El-Beialy, A.R. and Mostafa, Y.A. (2014) Virtual Techniques for Designing and Fabricating a Retainer. American Journal of Orthodontics and Dentofacial Orthopedics, 146, 394-398. https://doi.org/10.1016/j.ajodo.2014.01.025

[8] Johnston, C.D. and Littlewood, S.J. (2015) Retention in Orthodontics. British Dental Journal, 218, 119-122. https://doi.org/10.1038/sj.bdj.2015.47

[9] Stratemann, S.A., Huang, J.C., Maki, K., Miller, A.J. and Hatcher, D.C. (2008) Comparison of Cone Beam Computed Tomography Imaging with Physical Measures. Dentomaxillofacial Radiology, 37, 80-93. https://doi.org/10.1259/dmfr/31349994

[10] Hazeveld, A., Huddleston Slater, J.J.R. and Ren, Y. (2014) Accuracy and Reproducibility of Dental Replica Models Reconstructed by Different Rapid Prototyping Techniques. American Journal of Orthodontics and Dentofacial Orthopedics, 145, 108-115. https://doi.org/10.1016/j.ajodo.2013.05.011

[11] Porto, B.G., Porto, T.S. and Silva, M.B. (2014) Comparison of Linear Measurements and Analyses Taken from Plaster Models and Three-Dimensional Images. The Journal of Contemporary Dental Practice, 15, 681-687. https://doi.org/10.5005/jp-journals-10024-1599

[12] Radeke, J., von der Wense, C. and Lapatki, B.G. (2014) Comparison of Orthodontic Measurements on Dental Plaster Casts and 3D Scans. Journal of Orofacial Orthopedics, 75, 264-274. https://doi.org/10.1007/s00056-014-0217-9

[13] Lippold, C., Kirschneck, C. and Schreiber, K. (2015) Methodological Accuracy of Digital and Manual Model Analysis in Orthodontics-A Retrospective Clinical Study. Computers in Biology and Medicine, 62, 103-109.

[14] Dudic, A., Giannopoulou, C., Leuzinger, M. and Kiliaridis, S. (2009) Detection of Apical Root Resorption after Orthodontic Treatment by using Panoramic Radiography and Cone-Beam Computed Tomography of Super-High Resolution. American Journal of Orthodontics and Dentofacial Orthopedics, 135, 434-437.

[15] Luu, N.S., Nikolcheva, L.G. and Retrouvey, J.-M. (2012) Linear Measurements using Virtual Study Models. The Angle Orthodontist, 82, 1098-1106. https://doi.org/10.2319/110311-681.1

[16] Wiranto, M.G., Engelbrecht, W.P., Tutein Nolthenius, H.E., van der Meer, W.J. and Ren, Y. (2013) Validity, Reliability, and Reproducibility of Linear Measurements on Digital Models Obtained from Intraoral and Cone-Beam Computed Tomography Scans of Alginate Impressions. American Journal of Orthodontics and Dentofacial Orthopedics, 143, 140-147

[17] Berco, M., Rigali, P.H., Miner, R.M., DeLuca, S., Anderson, N.K. and Will, L.A. (2009) Accuracy and Reliability of Linear Cephalometric Measurements from Cone-Beam Computed Tomography Scans of a Dry Human Skull. American Journal of Orthodontics and Dentofacial Orthopedics, 136, 17.e1-e9.

[18] Kim, S.-H., Choi, Y.-S., Hwang, E.-H., Chung, K.-R., Kook, Y.-A. and Nelson, G. (2007) Surgical Positioning of Orthodontic Mini-Implants with Guides Fabricated on Models Replicated with Cone-Beam Computed Tomography. American Journal of Orthodontics and Dentofacial Orthopedics, 131, S82-S89. 